\title{
Pengolahan Sampah Organik Menjadi Biobriket Sebagai Energi Terbarukan
}

\author{
G.M Saragih $^{1^{*}}$, Marhadi ${ }^{2}$, dan Yulia Defriati ${ }^{3}$ \\ ${ }^{1,2,3}$ Program Studi Teknik Lingkungan, Fakultas Teknik, Universitas Batanghari \\ Jalan Slamet Riyadi, Kota Jambi \\ *correspondence e-mail: saragihguntar@gmail.com
}

\begin{abstract}
One of the uses of organic waste is processing it into biomass briquettes which can later be used as energy. Organic waste received is dry organic waste such as dry leaves, dry twigs, inorganic waste such as plastic waste which can be used as an adhesive in making waste biobriquettes. The purpose of processing organic and inorganic waste into energy is to benefit from the waste in the city of Jambi. The benefit obtained is to reduce waste which can be used as energy. The kerosene to LPG conversion program has resulted in a rapid increase in LPG consumption which domestic production cannot meet. This causes LPG imports to increase rapidly, so that if in 2007 the volume of LPG imports was still at 137 thousand tons, in 2011 it increased to 1,992 thousand tons or an increase of almost 15 times (Outlook Energi Indonesia 2013). The highest calorific value with the optimum composition is found in biobriquette sample 3 with a variation of the composition of $75 \%$ organic waste: $5 \%$ inorganic waste: $10 \%$ water: $10 \%$ glue, which is $19361 \mathrm{~J} / \mathrm{gr}$. The lowest ash content with the optimum composition was found in sample 3 with a variation of the composition of 75\% organic waste: 5\% inorganic waste: $10 \%$ water: 10\% glue, namely 5.06\%. The lowest water content with the optimum composition is found in sample 1 and sample 2 with a water content of $0.92 \%$, this is already in accordance with SNI for biobriquettes. The lowest CO content with the optimum composition is found in the biobriquette sample 1 with a variation of the organic composition of $85 \%$ : $5 \%$ inorganic: $5 \%$ water: $5 \%$ glue, which is $60.33 \mu \mathrm{g} / \mathrm{Nm}^{3}$.
\end{abstract}

Keywords: Organic waste, biomass briquettes, and waste energy.

\section{Pendahuluan}

Sampah merupakan masalah yang dihadapi oleh negaranegara maju maupun berkembang dan hingga saat ini penanganan serta pengelolaan sampah masih terus dikembangkan. Kota Jambi juga tidak terlepas dari permasalahan sampah, yang akan mencemari lingkungan bila tidak dikelola. Upaya dalam pengelolaan sampah kota Jambi adalah dengan cara memanfaatkan sampah.

Salah satu pemanfaatan sampah organik adalah dengan mengolahnya menjadi briket biomassa yang nanti bisa digunakan sebagai energi. Sampah organik yang diterima adalah sampah organik kering seperti daun kering, ranting kering, sampah anorganik seperti sampah plastik dapat digunakan sebagai perekat dalam pembuatan biobriket sampah. Tujuan pengolahan sampah organik dan anorganik menjadi energi adalah untuk mendapatkan manfaat dari sampah yang ada di kota Jambi. Manfaat yang diperoleh adalah mengurangi sampah yang bisa dimanfaatkan menjadi energi. Program konversi minyak tanah ke LPG menyebabkan peningkatan konsumsi LPG dengan cepat yang tidak dapat dipenuhi oleh produksi dalam negeri. Hal ini menyebabkan impor LPG meningkat dengan cepat, sehingga bila pada tahun 2007 volume impor LPG masih sebesar 137 ribu ton, pada tahun 2011 meningkat menjadi 1.992 ribu ton atau meningkat hampir 15 kali lipat (Outlook Energi Indonesia, 2013).

\section{Metode Penelitian}

\subsection{Tempat dan Waktu}

Pembuatan biobriket sampah organik dilakukan di Bank Sampah Bangkitku, pencampuran media, perekat dan pencetakan sampah organik dan anorganik dilakukan di Laboratorium Teknik Universitas Batanghari. Pengujian kadar air dan kadar karbon terikat di Laboratorium Teknik Universitas Batanghari, dan pengujian nilai kalor, kadar abu, dilakukan di Laboratorium Dasar dan Terpadu Universitas Jambi. Penelitan dilaksanakan pada bulan November 2019 Febuari 2020. Lokasi alamat Bank Sampah Bangkitku di : Jln. Jend. Basuki Rahmat, Pall Lima, Kec. Kota Baru, Kota Jambi.

\subsection{Bahan Baku}

Bahan baku yang digunakan pada penelitian ini adalah sebagai berikut :

1. Sampah organik kering :

- Daun bambu kering

- Kayu dan serbuk gergaji ( kayu punak dan kayu bulian)

- Ranting ketapang

2. Sampah anorganik kantong plastik bekas belanja berwarna hitam sebagai perekat.

\subsection{Peralatan}

Peralatan yang digunakan pada penelitian ini adalah sebagai berikut :

1. Karung beras untuk mengumpulkan sampah organik (daun kering, serbuk gergaji, ranting)

2. Tungku pirolisis untuk mengarangkan sampah organik (daun kering, serbuk gergaji, ranting);

3. Alat penumbuk (lumpang dan alu) digunakan untuk menumbuk bahan baku yang sudah diarangkan;

4. Cawan digunakan untuk tempat bubuk arang sampah organik (daun kering, serbuk gergaji, ranting);

5. Ayakan mesh 35 digunakan untuk mengayak bubuk sampah organik kering agar diperoleh ukuran partikel yang seragam;

6. Timbangan digital digunakan untuk menimbang berat bahan baku biobriket dengan berbagai variasi komposisi dan untuk menimbang berat sampah anorganik plastik (kantong bekas belanjaan) air dan lem;

7. Kantong plastik digunakan untuk tempat/wadah bahan baku biobriket yang sudah ditimbang berdasarkan variasi komposisinya; 
8. Label nama digunakan untuk menandai bahan baku biobriket berdasrkan variasi komposisinya;

9. Cawan digunakan untuk tempat melarutkan sampah plastik sebagai perekat

10. Kompor digunakan untuk memanaskan sampah anorganik

11. Pengaduk digunakan untuk mengaduk larutan sampah anorganik ketika dipanaskan agar tidak menggumpal serta untuk mengaduk adonan biobriket agar campuran merata;

12. Cetakan biobriket digunakan untuk mencetak adonan biobriket;

13. Nampan digunakan untuk meletakan biobriket yang telah dicetak;

14. Alat tulis digunakan untuk mencatat label biobriket dengan berbagai variasi;

15. Gelas ukur digunakan untuk mengukur banyaknya air yang digunakan untuk membuat larutan lem sebagai perekat

16. Oven digunakan untuk mengeringkan biobriket.

\subsection{Proses Pembuatan Briket}

1. Penyiapan bahan baku;

2. Pengarangan;

3. Penumbukan;

4. Pengayakan;

5. Pencampuran media;

6. Tahap pencetakan;

7. Pengeringan;

8. Tahap uji karakteristik

\section{Hasil dan Pembahasan}

\subsection{Nilai Kalor Biobriket Komposisi Optimum}

Nilai kalor merupakan salah satu parameter utama dalam menentukan kualitas briket. Hasil pengukuran nilai kalor biobriket sampah organik dan anorganik plastic berwarna hitam ( kantong plastik bekas belanjaan)

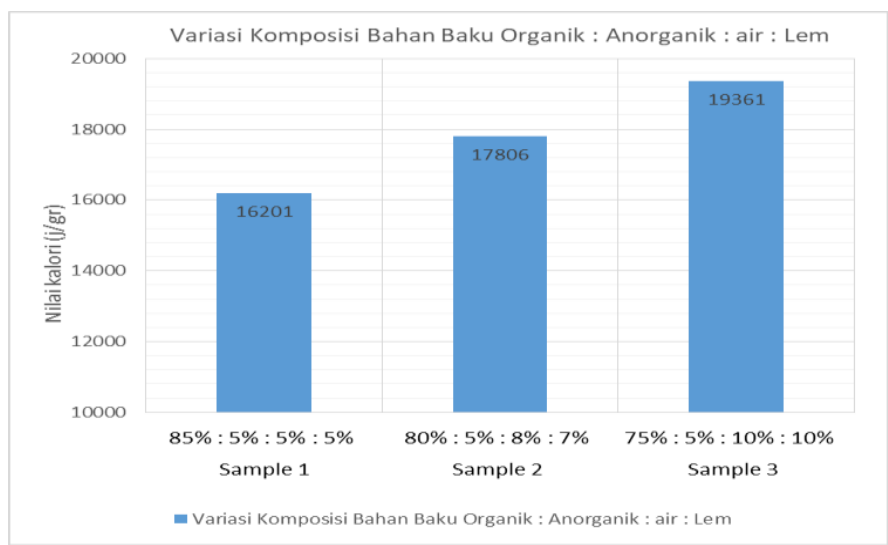

Gambar 1. Grafik pengaruh variasi komposisi bahan baku biobriket sampah organik terhadap nilai kalori

\section{Kadar Abu Biobriket Komposisi Optimum}

Abu merupakan bagian yang tersisa dari hasil pembakaran biobriket. Menurut Hendra dan Darmawan (2000), salah satu unsur kadar abu adalah silika dan pengaruhnya kurang baik terhadap nilai kalor yang dihasilkan. Kandungan abu yang tinggi dapat menurunkan nilai kalor briket arang sehingga kualitas briket arang tersebut menurun (Masturin A, 2002). Kadar abu yang dihasilkan juga sangat erat hubungannya dengan jenis bahan penyusun briket tersebut dan cara penggabungannya, serta mineral yang terkandung didalamnya. Hal ini sesuai dengan literatur Sudarmadji, dkk (2002), bahwa kandungan abu dan komposisinya tergantung pada macam bahan dan cara penggabungannya. Nilai kadar abu biobriket sampah organik dan anorganik plastik berwarna hitam ( kantong bekas belanjaan).

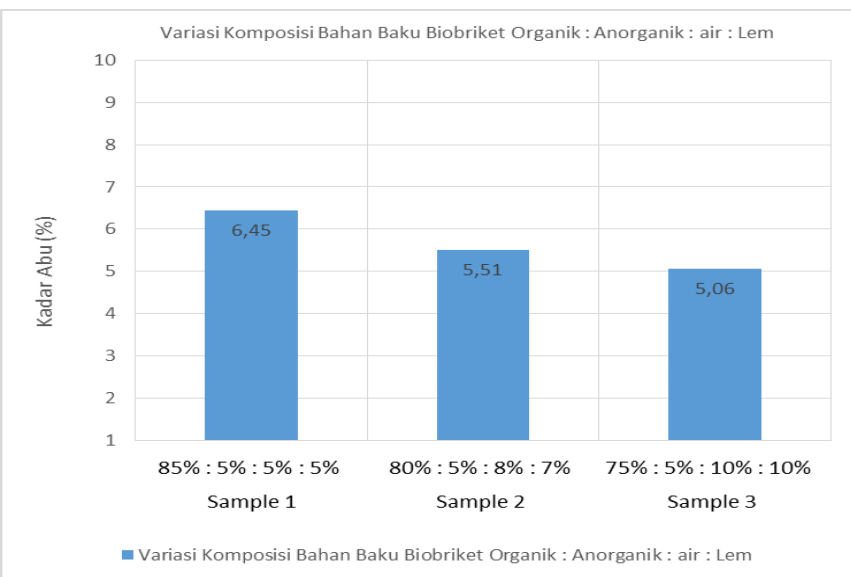

Gambar 2. Grafik pengaruh variasi komposisi bahan baku biobriket sampah organik terhadap kadar abu.

\section{Kadar Air Biobriket Komposisi Optimum}

Kadar air dalam briket dilakukan pengujiannya saat pengeringan briket dilakukan dengan metode pengeringan oven dengan suhu $105^{\circ} \mathrm{C}$ dan dengan melakukan penimbangan berulang kali sampai briket terlihat mengering dengan waktu yang tidak ditentukan dimana dengan rumus pengukuran kadar air untuk berat di lakukan perumusan (Jung and Wells,1997), dan dilakukan di Laboratorium Teknik Universitas Batanghari, dengan perumusan :

$\frac{m 1-m 2}{m 1} \times 100 \%=\%$

berat awal - berat ahkir setelah dioven, berikut penimbangan tiap sample :

1. Sample 1

Berat awal (m1) : $1102 \mathrm{gr}$

Berat ahkir (m2) : 86,2 gr

$$
\frac{1102-86,2}{1102} x 100 \%=0,92 \%
$$

2. Sample 2

Berat awal (m1) : 1203 gr

Berat ahkir (m2) : 88,01 gr

$$
\frac{1203-88,01}{1203} x 100 \%=0,92 \%
$$

3. Sample 3

Berat awal (m1) : 1352 gr

Berat ahkir (m2) : 92,8 gr

$$
\frac{1352-928}{1352} \times 100 \%=0,93 \%
$$

\section{Kadar Karbon Terikat ( CO ) Komposisi Optimum}

Karbon Monoksida (CO) adalah suatu gas tidak berwarna, tidak berbau yang dihasilkan oleh pembakaran tidak sempurna material yang mengandung zat arang atau bahan organik. Nilai kadar karbon terikat CO biobriket sampah organik dan anorganik plastik berwarna hitam (kantong bekas belanjaan). 


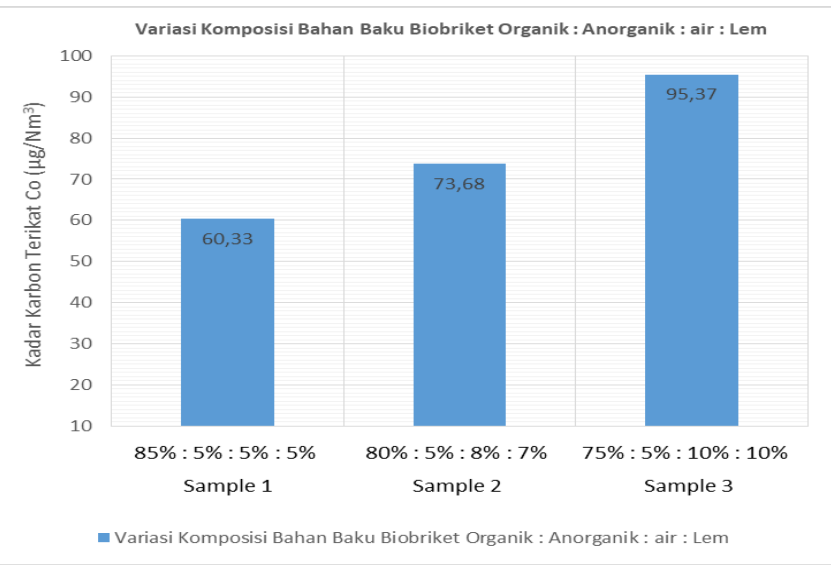

Gambar 3. Grafik pengaruh variasi komposisi bahan baku biobriket sampah organik terhadap kadar karbon terikat CO

Gambar diatas menunjukkan hasil optimum dari sampel biobriket sampah organik dan anorganik . Data hasil pengukuran nilai kalor, kadar abu, kadar air dan kadar karbon terikat $\mathrm{CO}$ dapat dijelaskan bahwa:

1. Hasil nilai kalor optimum terdapat pada sampel 3 dengan nilai kalor yaitu sebesar $19631 \mathrm{kal} / \mathrm{gr}$. Dari sample 3 terdapat kandungan organik sebesar $75 \%$ sebanding dengan nilai perekat agar dapat mempermudah saat pencetakan biobriket, dan agar nilai pembakaran biobriket sebanding dengan LPG ukuran $3 \mathrm{~kg}$, maka dipilihlah sampel 3, karena sampel 3 memiliki nilai kalor tertingi dikategorikan sebanding dengan LPG ukuran $3 \mathrm{~kg}$ sebagai alternatif LPG sebagai energi terbarukan. Selain itu sampel 3 mempunyai kekurangan dimana banyak kandungan lem sebesar $10 \%$ yang bisa mempengaruhi biaya pembuatan briket.

2. Hasil nilai kadar abu pada sampel 3 yaitu sebesar $5,06 \%$ tergolong tinggi sehingga dapat mencemari lingkungan. Jadi, sampel 3 dikategorikan optimum, karena agar mengurangi pencemaran lingkungan.

3. Hasil nilai kadar air pada sampel 1 dan 2 yaitu sebesar $0,92 \%$ tergolong rendah sehingga dikategorigakan optimum dan sudah sesuai standar SNI biobriket..

4. Hasil nilai kadar karbon terikat pada sample 1 yaitu sebesar $60,33 \mu \mathrm{g} / \mathrm{Nm}^{3}$ dikategorikan optimum karena pada sample 1 terendah sehingga mengurangi pencemaran lingkungan.

\section{Nilai Kalor Biobriket Komposisi Optimum}

Berdasarkan tabel 4.1 data hasil pengukuran nilai kalor biobriket sampah organik dan anorganik, menunjukkan bahwa nilai kalor tertinggi terdapat pada biobriket sample 3 dengan variasi komposisi organik 75\% : anorganik 5\% : air 10\% : lem $10 \%$ yaitu sebesar $19361 \mathrm{kal} / \mathrm{gr}$. Sementara nilai kalor terendah terdapat pada biobriket sample 1 dengan variasi komposisi organik $85 \%$ : anorganik 5\%: air 5\% : lem 5\% yaitu sebesar $16201 \mathrm{~J} / \mathrm{gr}$.

Biobriket dengan komposisi optimum terdapat pada biobriket sample 3 variasi komposisi organik 75\% : anorganik $5 \%$ : air $10 \%$ : lem $10 \%$ yaitu sebesar $19361 \mathrm{~J} /$ gr. Biobriket dengan komposisi optimum terdapat pada biobriket sample 3 sebagai pengganti LPG sebagai energi terbarukan biobriket harus memiliki nilai kalor tinggi untuk pembakaran yang tahan lama. LPG ukuran $3 \mathrm{~kg}$ memiliki nilai kalori sebesar 11.254,61 Kcal/Kg (Kementrian Energi dan Sumber Daya Mineral Direktorat Jendral Minyak dan Gas Bumi, 2007), sedangkan sample 3 memiliki nilai kalor $19361 \mathrm{~J} / \mathrm{gr}$ dengan bahan baku 75\% organik : 5\% anorganik : $10 \%$ air : $10 \%$ lem yang menghasilkan $1 \mathrm{~kg}$ briket berarti menghasilkan setara dengan LPG ukuran $5 \mathrm{~kg}$, maka dari itu briket bisa dikategorikan bisa digunakan untuk pengganti LPG sebagai energi terbarukan. Sementara nilai kalor terendah terdapat pada biobriket sampe 1 dengan variasi komposisi sampah organik $85 \%$ : sampah anorganik 5\% : air 5\% : lem 5\% yaitu sebesar $16201 \mathrm{~J} / \mathrm{gr}$. Komposisi optimum dari nilai kalor terdapat pada sample 3 .

\section{Kadar Air Biobriket Komposisi Optimum}

Setelah melakukan pengujian kadar air menggunakan metode pengeringan di oven dengan suhu $105^{\circ}$ C. Kadar air tertinggi terdapat pada biobriket sample 3 dengan variasi komposisi sampah organik $75 \%$ : sampah anorganik 5\% : air $10 \%$ : lem $10 \%$ yaitu sebesar $0,93 \%$, sedangkan kadar air terendah dengan sample 1 dan sample 2 dengan kadar air 0,92 $\%$. Ini udah sesuai dengan SNI biobriket. Pengujian kadar air ini dilakukan secara manual dengan metode pengeringan dengan menggunakan oven yang dilakukan di Laboratorium Teknik Universitas Batanghari.

\section{Kadar Karbon Terikat ( CO ) Komposisi Optimum}

Berdasarkan hasil tabel 4.3 data hasil pengukuran kadar karbon terikat $\mathrm{CO}$ biobriket sampah organik dan anorganik di atas, menunjukan bahwa nilai CO tertinggi terdapat pada biobriket sample 3 dengan variasi komposisi organik $75 \%$ : anorganik 5\% : air 10\% : lem 10\% yaitu sebesar 95,37 $\mu \mathrm{g} / \mathrm{Nm}^{3}$. Sedangkan terendah terdapat pada biobriket sample 1 dengan variasi komposisi organik $85 \%$ : anorganik 5\% : air $5 \%$ : lem $5 \%$ yaitu sebesar $60,33 \mu \mathrm{g} / \mathrm{Nm}^{3}$.

Biobriket dengan komposisi optimum terdapat pada yang kadar $\mathrm{CO}$ nya terendah dengan biobriket sample sample 1 dengan variasi komposisi organik $85 \%$ : anorganik 5\% : air $5 \%$ : lem $5 \%$ yaitu sebesar $60,33 \mu \mathrm{g} / \mathrm{Nm}^{3}$. Semakin banyak organik semakin tinggi kandungan $\mathrm{CO}$ nya, tetapi kandungan lem mempengaruhi nilai kadar CO nya sehingga sample 3 tidak dikategorikan yang optimum.

\section{Kesimpulan}

Berdasarkan hasil penelitian yang telah dilakukan dapat diambil kesimpulan sebagai berikut :

1. Nilai kalor tertinggi dengan komposisi optimum terdapat pada biobriket sample 3 dengan variasi komposisi sampah organik $75 \%$ : sampah anorganik 5\% : air 10\% : lem 10\% yaitu sebesar $19361 \mathrm{~J} / \mathrm{gr}$.

2. Kadar abu terendah dengan komposisi optimum terdapat pada sample 3 dengan variasi komposisi sampah organik $75 \%$ : sampah anorganik 5\% : air 10\% : lem 10\% yaitu sebesar $5.06 \%$.

3. Kadar air terendah dengan komposisi optimum terdapat pada sample 1 dan sample 2 dengan kadar air 0,92\%, ini udah sesuai dengan SNI biobriket.

4. Kadar CO terendah dengan komposisi optimum terdapat pada biobriket sample 1 dengan variasi komposisi organik $85 \%$ : anorganik 5\%: air 5\% : lem 5\% yaitu sebesar 60,33 $\mu \mathrm{g} / \mathrm{Nm}^{3}$. 


\section{Daftar Pustaka}

Andry, H. U. (2000). Aneka Tungku Sederhana. Yogyakarta : Penebar Swadaya.

Badan Standarisasi Nasional. (2000). Standar Nasional Indonesia Briket Arang Kayu (SNI 1-6235-2000). Jakarta.

Hendra dan Darmawan. (2000). Pengaruh Bahan Baku, Jenis Perekat dan Tekanan Kempa Terhadap Kualitas Briket Arang. Bogor: Pusat Penelitian dan Pengembangan Hasil Hutan.

Husada, T. I. (2008). Arang Briket Tongkol Jagung Sebagai Energi Alternatif. Laporan Penelitian/Artikel Ilmiah Program Penelitian Inovasi Mahasiswa Provinsi Jaw Tengah. Semarang.

Kementrian Lingkungan Hidup. (2009). Undang-Undang No. 32 Tahun 2009. Perlindungan Dan Pengelolaan Lingkungan Hidup. Jakarta.

Keputusan Menteri Perindustrian dan Perdagangan Republik Indonesia No.231/Mpp/kep/7/1997 Pasal 1. Prosedur Impor Limbah. Jakarta.

Lubis, H.A. (2011). Uji Variasi Komposisi Bahan Pembuat Briket Kotoran Sapi dan Limbah Pertanian. Universitas Sumatera Utara. Medan

Kusuma, Hendra. 2000. Perencanaan dan Pengendalian Produksi. Andi, Yogyakarta.

Masturin, A. (2002). Sifat Fisika dan Kimia Briket Arang dari Campuran Arang Limbah Gergajian Kayu [skripsi]. Bogor. Fakultas Kehutanan. Institut Pertanian Bogor.

Patabang, D. (2012). Karakteristik Termal Briket Arang Sekam Padi dengan Variasi Bahan Perekat. Jurnal Mekanikal. Vol. 3, No.2.

Puspita, D. (2015). Analisis Nilai Kalor Dan Kadar Abu Briket Bioarang Cangkang Kelapa Sawit dan Sekam Padi. Universitas Batanghari. Jambi.

Tarsito, T., et al. (2013). Pengaruh Variasi Komposisi Briket Organik Terhadap Temperatur Dan Waktu Pembakaran. Laboratorium Fisika Material Jurusan Fisika FSM Universitas Diponegoro. Vol. 16, No. 1.

Triana, D. (2011). Pengaruh Variasi Komposisi Bahan Briket Terhadap Laju Pembakaran. Universitas Batanghari. Jambi. 